\title{
Modulating $\alpha$-synuclein misfolding and fibrillation in vitro by agrochemicals
}

This article was published in the following Dove Press journal:

Research and Reports in Biology

22 March 201 I

Number of times this article has been viewed

\author{
Blanca A Silva' \\ Olof Einarsdóttirl \\ Anthony L Fink ${ }^{1, \dagger}$ \\ Vladimir N Uversky ${ }^{2,3}$ \\ 'Department of Chemistry and \\ Biochemistry, University of \\ California, Santa Cruz, CA, USA; \\ ${ }^{2}$ Department of Molecular Medicine, \\ University of South Florida, Tampa, \\ FL, USA; ${ }^{3}$ nstitute for Biological \\ Instrumentation, Russian Academy \\ of Sciences, Pushchino, Moscow \\ Region, Russia
}

tAnthony L Fink passed away

on March 2, 2008
Correspondence: Vladimir N Uversky Department of Molecular Medicine, University of South Florida,

I290I Bruce B Downs Blvd,

MDC 7, Tampa, FL 336/2-4799, USA

Email vuversky@helth.usf.edu
Abstract: A combination of spectroscopic techniques including atomic force microscopy (AFM) and transmission electron microscopy (TEM), was used to analyze the effect of chemically distinct agrochemicals (pesticides, herbicides, and fungicides) on the in vitro misfolding and aggregation of a presynaptic intrinsically disordered protein $\alpha$-synuclein. Despite their differences in chemical properties, almost all the compounds screened affected the $\alpha$-synuclein fibrillation in a concentration-dependent manner. The morphology of the aggregated $\alpha$-synuclein was characterized by AFM and TEM techniques. In addition to typical fibrils abundantly found at the equilibrium phase, this analysis revealed the existence of a noticeable nonfibrillar fraction where $\alpha$-synuclein was present as protofilaments, small oligomers, and large oligomeric species. The aggregated $\alpha$-synuclein samples were separated into soluble and insoluble fractions by ultracentrifugation and subjected to structural and morphological characterization. Attenuated total reflectance Fourier transform infrared spectroscopic analysis showed that the insoluble $\alpha$-synuclein fractions possessed a high content of ordered $\beta$-structure, whereas the $\beta$-structure content of the supernatant pool populated by oligomeric species was noticeably lower. This study provides evidence that chemically distinct agrochemicals can directly interact with $\alpha$-synuclein to induce structural changes and affect the fibrillation process of this important protein.

Keywords: Parkinson's disease, environmental toxins, intrinsically disordered protein

\section{Introduction}

A growing body of evidence suggests that various environmental toxins might represent potential risk factors promoting the development of the idiopathic forms of Parkinson's disease (PD). This has resulted in a new line of scientific research aimed at identifying these environmental factors, with major focus on agrochemicals, which often play a major role in triggering neurodegenerative conditions. ${ }^{1,2}$ A positive association between agrochemical exposure and PD has been established. ${ }^{3-11}$ Clinical, epidemiological, and basic research has noted that rural living, well-water drinking, farming, agriculture-related occupations, and direct pesticide exposure increase the risk of $\mathrm{PD}$ in individuals over the age of 50 years to about $7 \%$ compared with $1 \%$ in the general population. ${ }^{12-22}$

Although the environmental toxic exposure was linked to higher incidences of $\mathrm{PD}$, the precise molecular mechanisms of the toxin-induced neurodegeneration are not clear as of yet, and different hypotheses have been put forth to describe how these environmental factors can trigger the development of idiopathic PD. It is proposed that toxicant exposure might result in induced neuronal cell damage, which over time 
would trigger PD. ${ }^{1,2,23,24}$ Cell damage after exposure to toxic chemicals might result from the inhibition of complex I in the mitochondria, an event commonly leading to oxidative stress. ${ }^{12,25}$ Oxidative stress, being triggered by reactive oxygen species production, might cause selective neurodegenerative events. ${ }^{12,24-26}$ Furthermore, the direct interactions of $\alpha$-synuclein with agrochemicals were proposed to serve as one of the main events that ultimately lead to idiopathic forms of PD. ${ }^{7,13,22}$ The direct interactions of $\alpha$-synuclein and agrochemicals resulting in protein misfolding, aggregation, and fibril formation have been demonstrated mostly through in vitro studies. Therefore, in vitro agrochemical screening represents a useful tool for identifying potential neurotoxic compounds. Furthermore, this type of research provides data for proposing mechanistic models of toxicant-induced misfolding events taking place at the molecular level. Likewise, in vitro studies provide information for future development of suitable animal models, which could be used for subsequent neurotoxic investigations. Therefore, such in vitro studies broaden scientific research and can be used to complement different lines of invstigation towards better understanding of PD etiology.

In this study, an array of chemically distinct agrochemicals, including various pesticides, herbicides, and fungicides (see Table 1), was screened to assess their direct interaction with $\alpha$-synuclein and their effect on the fibrillation kinetics of this protein. First, an initial set of agrochemicals was screened at fixed concentrations to establish their direct interaction with $\alpha$-synuclein. Subsequently, a subgroup of these chemicals was further scrutinized in a concentration-dependent fashion to assess their effects on $\alpha$-synuclein misfolding, aggregation, and fibrillation. A combination of well established techniques, such as thioflavine T (ThT) in vitro fluorescence assay, transmission electron microscopy (TEM), atomic force microscopy (AFM), circular dichroism (CD) spectroscopy, and attenuated total reflectance Fourier transform infrared (ATR-FTIR) spectroscopy, was applied to provide insight into the effect of the various chemicals on the $\alpha$-synuclein fibrillation process.

\section{Materials and methods Materials}

ThT was obtained from Sigma-Aldrich (St Louis, MO, USA). Pesticides of high purity grade were obtained and used without further purification (Riedel-de Haen, Aldrich Chemical Co., Milwakee, WI, USA; Sigma-Aldrich Chemical Co., St. Louis MO, USA; or Chem Service, West Chester, PA, USA). All other chemicals used were of analytical grade from Fisher Chemicals (Fairlawn, NJ, USA) and Sigma-Aldrich, St. Louis MO, USA.

\section{Methods}

\section{Wild-type $\alpha$-synuclein expression and purification}

Human recombinant wild-type $\alpha$-synuclein was expressed using BL21 (DE3) Escherichia coli cells transfected with pRK172/ $\alpha$-synuclein wild-type plasmid (an invaluable gift kindly provided by R. Jakes and M. Goedert, Medical Research Council, Cambridge, UK). $\alpha$-Synuclein was expressed and purified using a modified method described previously. $^{27-29}$

\section{Aggregation and fibrillation of $\alpha$-synuclein ThT preparation}

ThT was prepared as a $1 \mathrm{mM}$ stock solution in nanopure water from a nanopure Diamond water system (Barnstead International, Dubuque, IA), filtered through a $0.2 \mu \mathrm{m}$ sterile syringe filter, (Whatman International LTD, Maidstone, England), light protected to prevent quenching, and stored at $4{ }^{\circ} \mathrm{C}$ until time of use. The ThT concentration was calculated by measuring the absorbance at $420 \mathrm{~nm}$ and using an experimentally determined and documented molar extinction coefficient value of $24,420\left(\mathrm{M}^{-1} \mathrm{~cm}^{-1}\right){ }^{30,31}$

\section{Protein preparation for ThT assay}

Immediately before use, $2-5 \mathrm{mg}$ of lyophilized $\alpha$-synuclein was dissolved in freshly prepared $4^{\circ} \mathrm{C} 1 \mathrm{mM} \mathrm{NaOH}$ solution. Afterwards, the $\mathrm{pH}$ was adjusted to $10 \pm 0.5$ with $100 \mathrm{mM}$ $\mathrm{NaOH}$ to solubilize any aggregated protein. The dissolved protein was incubated at room temperature for 10 minutes, and subsequently centrifuged for 30 minutes at 75,000 rpm in an air-driven ultracentrifuge (Beckman, Brea, CA), to isolate aggregated material. At the end of the centrifugation, the supernatant was carefully extracted. Subsequently, the $\mathrm{pH}$ was adjusted to 7.4 with addition of Tris-HCl buffer, $\mathrm{pH} 7.4$ and $1 \mathrm{mM} \mathrm{HCl}$. The protein purity was monitored by sodium dodecyl sulfate polyacrylamide gel electrophoresis (SDS-PAGE), fluorescence emission signal at $305 \mathrm{~nm}$, and electrospray ionization mass spectrometry (ESI-MS), while the protein concentration was determined by measuring ultraviolet (UV) absorbance signal at $275 \mathrm{~nm}$ using the extinction coefficient of $0.40 \mathrm{mg}^{-1} \mathrm{~cm}^{2}$.

\section{Preparation of $\alpha$-synuclein fibrils and aggregates}

$\alpha$-Synuclein fibrils and aggregates were produced through $\alpha$-synuclein fibrillation assays which monitored changes in the ThT fluorescence emission signal at $482 \mathrm{~nm}$ while exciting at $450 \mathrm{~nm}$. At the beginning of the fibrillation studies, protein samples were predominantly monomeric and did not contain noticeable amounts of any oligomeric forms. 
Table I The chemical structures of the agrochemicals, herbicides, pesticides, and fungicides used in this study

\begin{tabular}{|c|c|c|c|}
\hline Pesticide & Structure & Chemical class & Use \\
\hline Diuron $^{\mathrm{a}}$ & $\mathrm{H}$ & Urea & $\begin{array}{l}\text { Herbicide } \\
\text { Breakdown } \\
\text { product }\end{array}$ \\
\hline Trufluralin $^{\mathrm{b}}$ & & Dinitroaniline & Herbicide \\
\hline Paraquat $^{c}$ & cr & Bipyridium & Herbicide \\
\hline $\mathrm{DDT}^{\mathrm{d}}$ & & Organochlorine & Insecticide \\
\hline $\mathrm{DDE}^{\mathrm{e}}$ & & $\begin{array}{l}\text { Organochlorine } \\
\text { (DDT breakdown product) }\end{array}$ & Insecticide \\
\hline $\begin{array}{l}\text { Kepone } \\
\text { (chlordecone) }^{f}\end{array}$ & $\mathrm{Cl}$ & Organoclorine & Insecticide \\
\hline Rotenone ${ }^{g}$ & & Botanical & Insecticide \\
\hline
\end{tabular}


Table I (Continued)

\begin{tabular}{|c|c|c|c|}
\hline Pesticide & Structure & Chemical class & Use \\
\hline Captan $^{h}$ & & Thiophthalimide & Fungicide \\
\hline Chlorthalonil' & & $\begin{array}{l}\text { Substituted } \\
\text { benzene }\end{array}$ & Fungicide \\
\hline Iprodionej & & Dicarboximide & $\begin{array}{l}\text { Fungicide } \\
\text { Breakdown } \\
\text { product }\end{array}$ \\
\hline Lindane $^{k}$ & & Organochlorine & $\begin{array}{l}\text { GUP } \\
\text { Fungicide } \\
\text { Insecticide } \\
\text { Rodenticide }\end{array}$ \\
\hline Maneb' & & $\begin{array}{l}\text { Ethylene } \\
\text { Dithiocarbamate }\end{array}$ & Fungicide \\
\hline Ziram $^{m}$ & & Dithiocarbamate & $\begin{array}{l}\text { Fungicide } \\
\text { Microbicide } \\
\text { Dog/cat } \\
\text { repellent }\end{array}$ \\
\hline
\end{tabular}

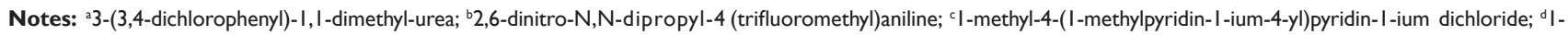
chloro-4-[2,2,2-trichloro-I-(4-chlorophenyl)ethyl]benzene; ${ }^{\mathrm{e}}$-chloro-4-[2,2-dichloro-I-(4-chlorophenyl)vinyl]benzene; ${ }^{\mathrm{f}} \mathrm{I}, 2,3,5,6,7,8,9,10,10$-Deca chloro[5.2.I .0(sup 2,6).0(sup 3,9).0(sup 5,8)]decano-4-one; $8(\mathrm{I})$ Benzopyrano(3,4-b)furo(2,3-h)(I)benzopyran-6(6aH)-one; ${ }^{\text {h2 }}$-(trichloromethylsulfanyl)-3a,4,7,7a-tetrahydroisoindole-I,3-dione; ${ }^{\prime}$ I,3Benzenedicarbonitrile,2,4,5,6-tetrachloro; 33-(3,5-dichlorophenyl)- $\mathrm{N}$-isopropyl-2,4-dioxo-imidazolidine-I-carboxamide; ${ }^{\mathrm{k}}$ ( I a,2a,3b,4a,5a,6b)-I,2,3,4,5,6-Hexachlorocyclohexane; 'Mn [2-(sulfidocarbothioylamino) ethylamino]methanedithioate; ${ }^{\mathrm{Z}} \mathrm{Zn} \mathrm{N}, \mathrm{N}$-dimethylcarbamothioate carbamothioate.

Abbreviations: DDE, dichlorodiphenyldichloroethylene; DDT, dichlorodiphenyltrichloroethane; GUP, general use pesticide.

Assay solutions contained $\alpha$-synucelin at a concentration of $1.0 \mathrm{mg} / \mathrm{mL}, 20 \mathrm{mM}$ ThT with various concentrations of agrochemicals as indicated. A volume of $150 \mu \mathrm{L}$ of the mixture was pipetted into a well of a 96-well plate (white plastic, clear bottom), and an eighth in. diameter. Teflon sphere (McMaster-Carr, Los Angeles, CA) was added. Each sample was run in triplicate or quadruplicate. The plates were sealed with Mylar plate sealers (Dynex, Pewaukee, WI). The plate was loaded into a fluorescence plate reader (Fluoroskan
Ascent; Thermo Scientific, Waltham, MA) and incubated at $37^{\circ} \mathrm{C}$ with shaking at $600 \mathrm{rpm}$ with a shaking diameter of 2 $\mathrm{mm}$. The fluorescence was measured at $30 \mathrm{~min}$ intervals with a sampling time of $100 \mathrm{~ms}$

\section{Pesticide assay preparation}

ThT assay samples contained 1.0 or $0.5 \mathrm{mg} / \mathrm{mL}(70 \mu \mathrm{M}$, $35 \mu \mathrm{M}$ ) of $\alpha$-synuclein in $20 \mathrm{mM}$ Tris- $\mathrm{HCl}$ buffer, $\mathrm{pH} 7.5$, containing $100 \mathrm{mM} \mathrm{NaCl} / 20 \mu \mathrm{MThT}, 0.02 \% \mathrm{v} / \mathrm{v} \mathrm{NaN}_{3}$. In a 
set of experiments, the pesticides were added at submolar, equimolar, or in excess amounts. The pesticides were dissolved in a variety of high purity solvents, water, ethanol, acetone, and dimethylsulfoxide (DMSO) as needed, and a respective protein-solvent control assay was monitored. Samples were prepared in sufficient amounts for a minimum of three to five replicates; $120 \mu \mathrm{L}$ aliquots were distributed in a 96-well microtiter plate (Corning Inc., Corning, NY).

\section{Data evaluation of kinetics of fibril formation}

The kinetics of $\alpha$-synuclein fibril formation is described by a nucleation-dependent mechanism. This process is characterized by a sigmoidal curve defined by an initial lag phase, a period where no ThT fluorescence signal intensity change is observed. This initial phase is followed by an elongation period or growth phase, in which the ThT fluorescence signal increases as fibril elongation takes place, and ultimately a plateau is reached signaling the end of fibril formation. ${ }^{11,32}$ The resulting data consisted of a fluorescence signal of ThT, expressed in arbitrary units, displayed over time in hours. The data generated from each vial were used to plot the ThT fluorescence signal as a function of time, and fitted to a sigmoidal curve using Equation 1:33-35

$$
Y=y_{i}+m_{i} x+\frac{y_{f}+m_{f} x}{1+e^{-\left[\frac{\left(x-x_{o}\right)}{\tau}\right]}}
$$

Here, $y$-values correspond to fluorescence intensities and $x$-values correspond to time, $m_{i}-$ and $m_{f}$-values correspond to the respective slope values at initial and equilibrium phases, and $x_{o}$ represents the time at $50 \%$ maximal fluorescence. From these parameters, the lag time is estimated as $x_{o}-2 \tau$, and the apparent rate constant, $k_{\text {app }}$, for fibril growth is estimated as $1 / \tau$. This expression provides an efficient method to compare the kinetics of fibrillation; however, it does not provide insightful information of the events that occur at the molecular level.

\section{TEM}

TEM was used to analyze the morphology and to estimate the sizes of the fibrils and aggregates of $\alpha$-synuclein. Samples for TEM analysis were prepared by extracting a $25-\mu \mathrm{L}$ aliquot of fibrillated $\alpha$-synuclein that was diluted 1:4 with double distilled (ddi) water to a final volume of $100 \mu \mathrm{L}$, and followed by 45 minutes centrifugation at 14,000 rpm. After centrifugation, the supernatant was carefully removed, and the precipitated sample was resuspended again to $100 \mu \mathrm{L}$ with ddi water and centrifuged at 14,000 rpm for 45 minutes.
Next, the supernatant was carefully removed, and the final washed precipitate sample resuspended to $25 \mu \mathrm{L}$ with ddi water. TEM samples were prepared by placing an $8-\mu \mathrm{L}$ fibril droplet on a glow discharged 300-mesh copper grid coated with Formvar/carbon B support film (Ted Pella Inc., Redding, CA). The sample was allowed to dry for five minutes, and the excess liquid was blot-dried with filter paper by gently tapping the edge of the grid. Subsequently, fibrils were negatively stained with $2 \%(\mathrm{w} / \mathrm{v})$ aqueous uranyl acetate. The copper grids were surveyed to assess overall sample morphology. TEM images of fibril and aggregates samples were obtained using a JEM-100B transmission electron microscope (JEOL, Tokyo, Japan) operating with an accelerating voltage of $80 \mathrm{kV}$. Image magnifications were taken in general at $75,000 \times$ or as specified in the text where pertinent. Images were generated with Gatan Digital Micrograph software (v3.61; Gatan Inc., Pleasanton, CA).

\section{AFM}

AFM images were obtained using a PicoScan Plus microscope equipped with MAC mode (Molecular Imaging, Phoenix, AZ). To obtain images, ultra-sharp NCS16/AlBS probes (Mikro-Masch, San Jose, CA, USA) were used. AFM scanning was done with a force constant of $45 \mathrm{~N} / \mathrm{m}$ and $170 \mathrm{kHz}$ resonance frequency. Typical scan rates ranged from 0.5 to 1.0 lines per second. Samples for AFM analysis were prepared on freshly cleaved mica substrates by placing a $5-\mu \mathrm{L}$ aliquot sample of 1:5 diluted fibrillated $\alpha$-synuclein, with $20 \mathrm{mM}$ phosphate-buffered saline at $\mathrm{pH} 7.5$, and adding $5-\mu \mathrm{L}$ of $1 \mathrm{M}$ $\mathrm{NaCl}$. The $\alpha$-synuclein/ $\mathrm{NaCl}$ sample on mica was held along the edge with tweezers and gently tilted several times to ensure formation of a homogeneous layer. Next, the samples were allowed to incubate from a minimum of 4 hours to overnight, followed by extensive rinsing with ddi water to remove salt and unbound protein. After rinsing, the samples were allowed to air-dry in a loosely covered Petri dish. Subsequently, AFM images were obtained as described above. Diameters of aggregates and fibril forms of $\alpha$-synuclein AFM images were estimated from height measurements using PicoScan 5 (Molecular Imaging, San Diego, CA) and SPIP software (Image Metrology A/S, Hørsholm, Denmark).

\section{FTIR measurements}

To perform the ATR-FTIR analysis, hydrated thin sample films were prepared and analyzed as previously described. ${ }^{36,37}$ ATR-FTIR measurements were conducted to monitor structural and conformational changes at the end of the fibrillation process, or to monitor changes over the course 
of the fibrillation. Essentially, a $25 \mu \mathrm{L}$ sample of interest (ie, monomeric, aggregated, or fibrillated) of 0.5 or $1.0 \mathrm{mg} / \mathrm{mL}$ $\alpha$-synuclein was placed on a germanium trapezoidal element. The sample was gently dried with a stream of nitrogen gas. Subsequently, ATR-FTIR spectra were recorded on a Thermo-Nicolet Nexus 670 FTIR spectrometer (Thermo Scientific, West Palm Beach, FL) equipped with a MCT (mercury cadmium telluride) detector and an out-of-compartment $72 \mathrm{~mm} \times 10 \mathrm{~mm} \times 6 \mathrm{~mm}, 45^{\circ}$ germanium trapezoidal internal reflectance element. The resulting 1024 interferograms from 1700 to $1600 \mathrm{~cm}^{-1}$ were co-added at $1 \mathrm{~cm}^{-1}$ resolution. Data analysis was conducted using GRAMS32 (Galactic Industries, Thermo Scientific) and SigmaPlot ${ }^{\circledR}$ (Systat Software, Inc) software. Secondary structural changes were assessed by comparing ATR-FTIR spectral signals of the different $\alpha$-synuclein species.

\section{CD measurements}

$\alpha$-Synuclein secondary structure propensity was analyzed by $\mathrm{CD}$ spectroscopy in the far-UV region. $\mathrm{CD}$ studies were conducted in the presence of pesticides to assess interactions of pesticides with protein and to monitor structural changes induced in protein by these interactions. To conduct these experiments, 1.0 and $0.5 \mathrm{mg} / \mathrm{mL} \alpha$-synuclein samples were titrated with pesticide, and spectral properties of the reaction mixture were monitored after 10 minutes incubation using the $0.2 \mathrm{~mm}$ path-length cell. Averages of four scans were obtained at $1 \mathrm{~nm}$ step increments at $1.5 \mathrm{~nm}$ band width and 8 seconds integration time.

\section{Results}

\section{$\alpha$-Synuclein expression and purification}

$\alpha$-Synuclein was expressed and purified using a modified method described previously. ${ }^{27-29}$ In summary, the estimated purity of $\alpha$-synuclein was greater than $95 \%$ as determined by SDS-PAGE. A molecular mass of $14,458 \pm 2$ Da was obtained for the purified protein by mass spectroscopy, which was consistent with the theoretical molecular mass of $\alpha$-synuclein (14,460 Da). The far-UV CD spectrum of purified $\alpha$-synuclein is typical of an unstructured, random, coil-like polypeptide chain, which is consistent with the natively unfolded nature of $\alpha$-synuclein under physiologic conditions in vitro. ${ }^{38}$ Since the wild-type $\alpha$-synuclein does not contain tryptophans, its fluorescence emission spectrum is typical of a tyrosine-containing protein. Based on all these criteria, the purified materials contained homogeneous and pure protein samples suitable for structural and aggregation analysis in vitro.

\section{Kinetics of $\alpha$-synuclein fibril formation in the presence of pesticides}

Earlier studies revealed that $\alpha$-synuclein might interact with agrochemicals in vitro, resulting in protein misfolding, aggregation, and fibril formation. , $8,11,13,23,24,39$ The objective of our study was to further strengthen the epidemiological and clinical evidence that linked pesticide exposure with increased incidence of PD as a result of direct interaction of pesticides with $\alpha$-synuclein. ${ }^{40-43}$ To this end, the effects of various agrochemicals on the fibrillation kinetics of wildtype $\alpha$-synuclein were monitored using the characteristic changes in the fluorescence properties of the histological dye ThT. Table 1 lists various agrochemicals analyzed in our study and shows that the compounds can be grouped into herbicides, fungicides, synthetic pesticides, and botanic pesticides. The changes in the ThT florescence intensity have been widely used to monitor the fibril formation by various proteins because of its characteristic enhancement induced by the binding of the dye to the fibrils. ${ }^{44-46}$ Figure 1 shows the time-dependent changes in the ThT fluorescence intensity induced by incubation of $\alpha$-synuclein $(35 \mu \mathrm{M})$ at $\mathrm{pH} 7.5$ and $37^{\circ} \mathrm{C}$ in the absence or presence of illustrative agrochemicals, kepone, captan, paraquat, ziram, dichlorodiphenyldichloroethylene (DDE), and rotenone. Table 2 represents the results of these studies for all the compounds analyzed and clearly shows that these compounds affected the fibrillation of $\alpha$-synuclein in different ways. Many of them accelerated the rate of fibril formation under the experimental conditions in a concentration-dependent manner. Among the most efficient accelerators of $\alpha$-synuclein fibrillation were the pesticides, dichlorodiphenyltrichloroethane (DDT), kepone, and rotenone, as well as the herbicides, diuron, paraquat, and trifluralin (Table 2). The fibrillation-accelerating effects of rotenone are noteworthy because this pesticide is known to induce major PD symptoms in rats, and earlier molecular studies have demonstrated that rotenone disrupts complex I in mitochondrial respiration. ${ }^{8,10}$ Table 2 also shows that the majority of pesticides tested accelerated the rate of fibrillation. These results are in agreement with previous findings, in which the accelerated $\alpha$-synuclein fibril formation was induced by addition of several common pesticides. . 13,23,24 $^{2}$ The exceptions are the fungicides maneb and captan, the addition of which produced delayed fibril formation (Table 2). Another interesting observation is that the addition of the agrochemicals mostly affected the lag-time duration, whereas the fibril elongation rate was mostly unaffected by the presence of the compounds (Table 2). 


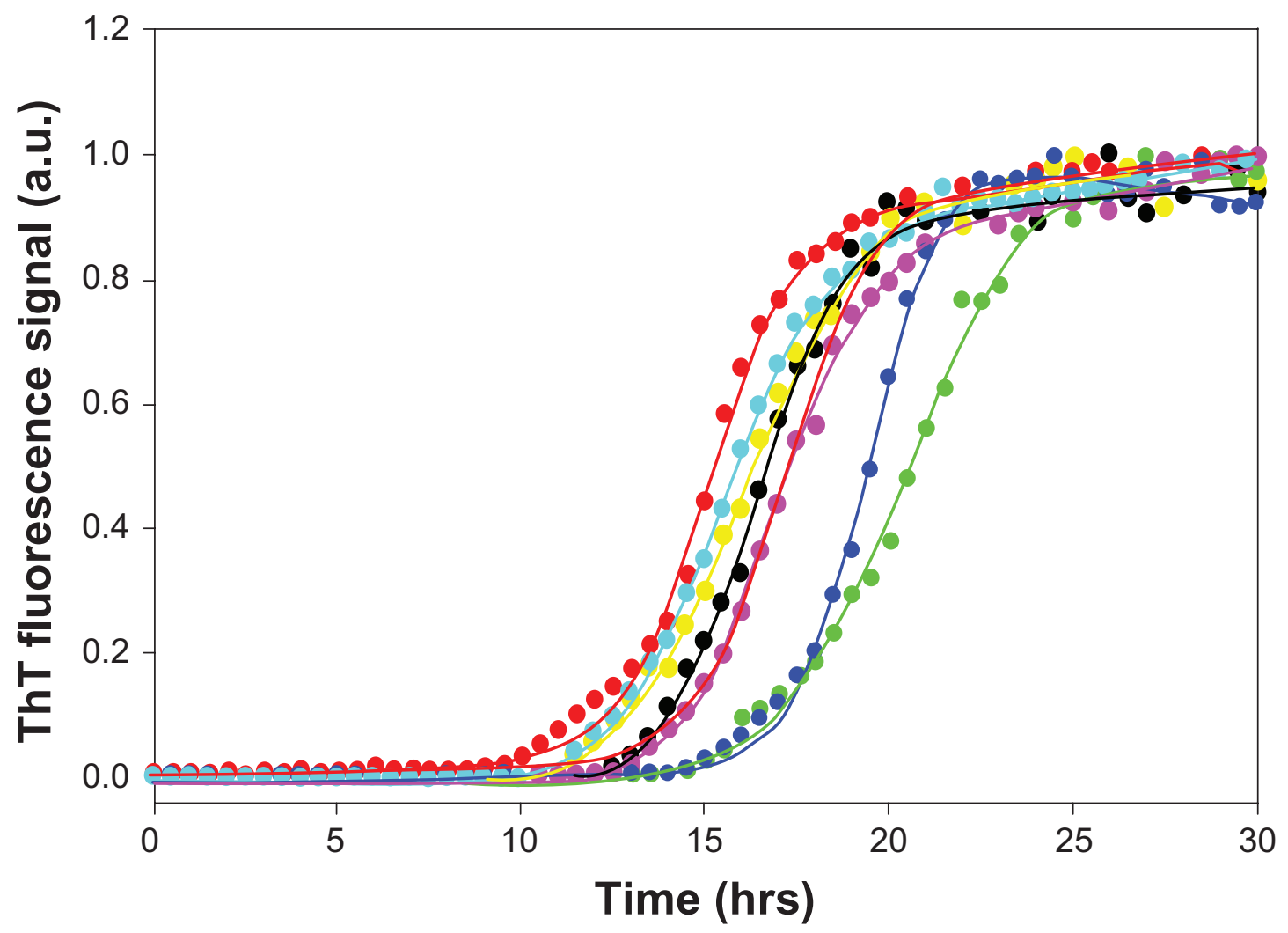

Figure I Illustrative kinetics of $35 \mu \mathrm{M} \alpha$-synuclein fibrillation in the presence of various pesticides dissolved in DMSO (black, control; red, kepone; green, captan; yellow, paraquat; blue, ziram; pink, DDE; cyan, rotenone). Samples were incubated at $37^{\circ} \mathrm{C}$ in $50 \mathrm{mM}$ phosphate buffer pH 7.5 in the presence of agrochemicals at $105 \mu \mathrm{M}$ with constant stirring. Fibril formation was monitored with the ThT fluorescence assay.

Abbreviations: a.u., arbitrary units; DDE, dichlorodiphenyldichloroethylene; DMSO, dimethylsulfoxide; ThT, thioflavine T.

The effects observed for the fungicide maneb are particularly interesting and consistent with previously published work. ${ }^{10,47}$ Although the effects of maneb are not as profound as those of DDT, rotenone, or trifluralin, the neurotoxicity of maneb is enhanced when present in combination with other chemicals in the reaction mixture. It has been established that maneb acts synergistically in the presence of paraquat in mouse models, and the end result was characterized by altered motor activity, damage to nigral cell bodies, and striatal terminals. ${ }^{32,47}$ This synergistic behavior is crucial because individuals subject to pesticide exposure are likely to be exposed to a combination of toxicants through their daily occupational activities. Therefore, the synergistic interaction of pesticides must be considered when studying the role environmental toxins play in idiopathic forms of PD. Furthermore, agricultural workers can come into contact with a particular pesticide at any given time, but as seasons change, different pesticides are used. The net result is an overlap and exposure to a complex mixture of pesticides, herbicides, and fumigants which together exert similar effects to those observed in laboratory studies.

The fibrillation modulating effects of the agrochemicals were further investigated by varying their concentrations in the presence of fixed amounts of $\alpha$-synuclein $(35 \mu \mathrm{M}$ or $70 \mu \mathrm{M})$. Figure 2 shows that all three classes of agrochemicals, pesticides (DDT, DDE, and kepone), herbicides (paraquat and trifluralin), and fungicide (captan), affected the efficiency of $\alpha$-synuclein fibrillation in a concentration-dependent manner. With the exception of captan, the fibrillation lag-time decreased with an increase in the chemical concentration; increase in captan concentration resulted in a progressive increase of the lag-time.

We also established that in the presence of some of the agrochemicals, $\alpha$-synuclein fibrillation displayed a complex pattern, suggesting that at early fibrillation steps, some prefibrillar species are formed that are able to bind ThT. This was evidenced by the sequential ThT fluorescence signal enhancement, where the initial fluorescence increase was followed by a second signal enhancement phase (data not shown).

The final ThT fluorescence intensity was different for the fibrils formed in the presence of different pesticides. A possible explanation is that the ThT signal intensity is proportional to the amount of fibrils present. However, this is not always the case, and the ThT fluorescence signal can also be affected by the binding of ThT to partially folded intermediate species 
Table 2 Kinetic parameters of $\alpha$-synuclein $(35 \mu \mathrm{M})$ fibrillation in the presence of various agrochemicals in comparison with the control (the table also includes some chemical properties of these agrochemicals)

\begin{tabular}{|c|c|c|c|c|c|c|}
\hline Agrochemical & $\begin{array}{l}\text { lagtime }{ }^{\text {agro/ }} \\
\text { lagtime }^{c}\end{array}$ & $\mathbf{k}_{\text {app }}^{\text {agro }} / k_{\text {app }}^{c}$ & $\begin{array}{l}\text { Number of } \\
\text { halogen atoms }\end{array}$ & $\begin{array}{l}\text { Number of } \\
\text { carbon cycles }\end{array}$ & $\begin{array}{l}\text { Octanol/water } \\
\text { partition } \\
\text { coefficient } \\
\left(\log K_{o w}\right) \\
\end{array}$ & $\begin{array}{l}\text { Solubility in } \\
\text { water }(\mathrm{mg} / \mathrm{L})\end{array}$ \\
\hline Rotenone & 0.322 & 0.877 & 0 & 5 & 4.10 & 0.20 \\
\hline Diuron & 0.323 & 0.952 & 2 & 1 & 2.68 & 36.4 \\
\hline DDT & 0.330 & 0.835 & 5 & 2 & 6.91 & $5.50 \times 10^{-3}$ \\
\hline Paraquat & 0.347 & 0.785 & 2 & 2 & -4.22 & Soluble \\
\hline Kepone & 0.451 & 0.895 & 10 & 6 & 5.41 & 2.70 \\
\hline Trifluralin & 0.481 & 0.900 & 3 & I & 5.34 & 18.4 \\
\hline Iprodione & 0.546 & 0.870 & 2 & 2 & 3.00 & 13.9 \\
\hline DDE & 0.583 & 1.000 & 4 & 2 & 6.51 & 0.04 \\
\hline Lindane & 0.671 & 0.800 & 6 & 1 & 3.72 & 7.3 \\
\hline Chlorthalonil & 0.715 & 0.800 & 4 & I & 3.05 & 0.81 \\
\hline Ziram & 1.253 & 0.893 & 0 & 0 & 1.23 & 65.0 \\
\hline Captan & 1.428 & 1.099 & 3 & 2 & 2.35 & 5.1 \\
\hline Maneb & 1.922 & 1.136 & 0 & 0 & 0.62 & 6.0 \\
\hline
\end{tabular}

Notes: Since there was noticeable variability between the different sets of experiments due to the fact that different agrochemicals, being poorly soluble in water, were dissolved in different organic solvents, qualitative interpretations of the data should be made with caution. Due to the mentioned variability between the different sets of experiments, the results were normalized to the kinetic parameters derived for the corresponding controls, where $\alpha$-synuclein was fibrillated alone but in the presence of the corresponding amount of the corresponding organic solvent.

Abbreviations: DDE, dichlorodiphenyldichloroethylene; DDT, dichlorodiphenyltrichloroethane.

and/or the binding to oligomer forms. ${ }^{48,49}$ Furthermore, the ThT fluorescence intensity can be affected by the presence of compounds that act as competitors or alter the ThT binding to fibrils. Finally, compounds can quench or interfere in some other way with the ThT fluorescence signal. ${ }^{48}$

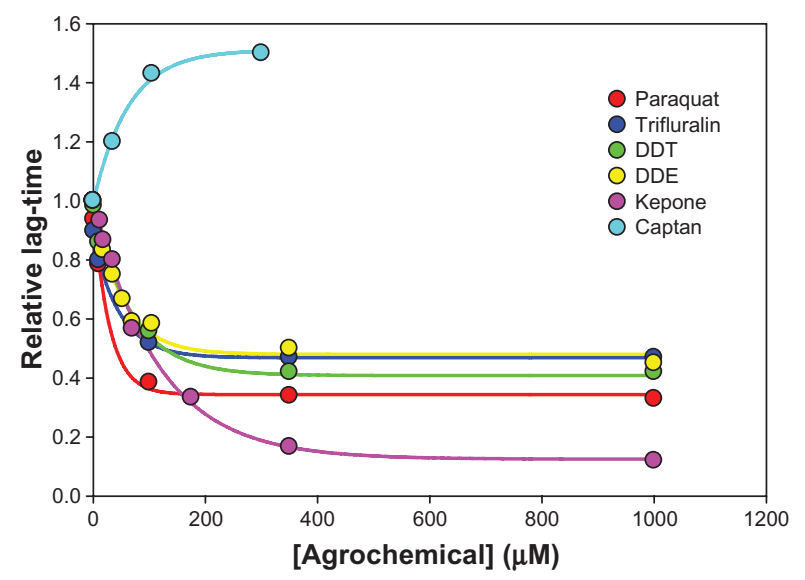

Figure 2 Concentration dependence of the effect of various agrochemicals on $35 \mu \mathrm{M} \alpha$-synuclein fibrillation. Since addition of the agrochemicals typically had minor effects on the elongation rates, only the data for the lag-time only are shown. Due to some variability between the different sets of experiments, the results were normalized to the kinetic parameters derived for the corresponding controls. Here, relative lag-times were calculated as lag-time measured in the presence of a given agrochemical divided by lag-time of the corresponding control, where $\alpha$-synuclein was fibrillated alone but in the presence of the corresponding amount of the respective organic solvent. Data are shown for paraquat, trifluralin, DDT, DDE, kepone, and captan. Agrochemical concentration was varied by changing its amount in the same amount of solvent.

Abbreviations: DDE, dichlorodiphenyldichloroethylene; DDT, dichlorodiphenyltrichloroethane.

\section{Morphology of the $\alpha$-synuclein fibrils and aggregates}

TEM and AFM were used to analyze the morphologies of the $\alpha$-synuclein fibrils and other aggregated species formed in the presence of the different agrochemicals. The results of this analysis are shown in Figures 3 and 4, respectively. In general, the analysis revealed a good correlation between the ThT fluorescence intensity and the amount of fibrils detectable in the corresponding TEM images. TEM micrograph analysis showed the presence of nonbranched fibrils, with dimensions on average of $\sim 15-25 \mathrm{~nm}$ wide with regular twisting pitch of $\sim 60 \mathrm{~nm}$ (shown by arrows in some TEM images, see Figure 3). Figure 3 shows that fibrils formed in the presence of different agrochemicals were characterized by the different morphology (ie, straight, curved, short, long, clumped, nonclumped, thick, thin). It is tempting to propose that because the morphology of fibrils was dependent on the incubation conditions, the fibrils may be formed via different pathways and the choice of a given fibrillation pathway could be determined by the environmental peculiarities. However, this conclusion is not based on the systematic morphological analysis of fibrils formed under different conditions, and more detailed and comprehensive analysis is needed.

Figure 4 represents AFM micrographs of $\alpha$-synuclein aggregates formed in the absence or presence of various agrochemicals mostly prior to fibril formation (except for kepone). Figure 4 clearly shows that different agrochemicals stabilize 

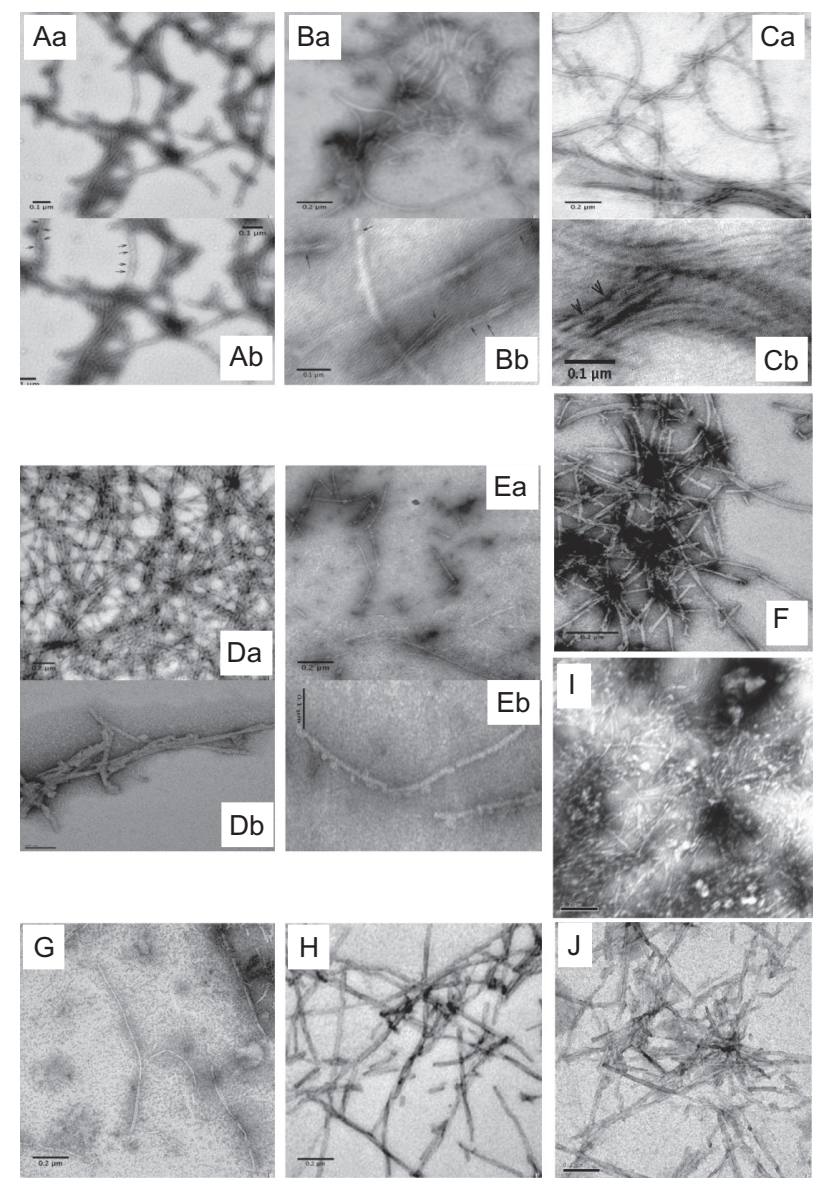

Figure 3 Negatively stained transmission electron micrographs of $\alpha$-synuclein fibrillated in the absence ( $\mathbf{A} \mathbf{a}$ and $\mathbf{A b}$ ) and presence of selected agrochemicals: DDT ( $\mathbf{B a}$ and $\mathbf{B b}$ ), paraquat ( $\mathbf{C a}$ and $\mathbf{C b})$, rotenone ( $\mathbf{D a}$ and $\mathbf{D b})$, maneb (Ea and $\mathbf{E b}$ ), diuron (F), iprodine (G), lindan (H), thiram (I), and trifluralin (J). I00- and 200-nm scale bars are shown for comparison and length assessment. All images were acquired at the magnification of 75,000 . Arrows indicate fibrils with noticeable pitch. Abbreviation: DDT, dichlorodiphenyltrichloroethane.

different prefibrillar aggregates. AFM micrographs showed a large population consisting of small and large oligomers with a smaller sample of fibrils present. The fibril widths were estimated to be in the range of $\sim 15-30 \mathrm{~nm}$. Two types of oligomers were found, with heights of $\sim 3-6 \mathrm{~nm}$ for the smaller oligomers (mostly found in the control experiments), and heights of $\sim 15-30 \mathrm{~nm}$ for the larger ones (detected in the presence of agrochemicals). Interestingly, Figure 5 shows that different kepone concentrations induced morphologically distinct aggregated species of $\alpha$-synuclein.

\section{Pesticides induce structural changes in $\alpha$-synuclein}

Taking into account that fibril formation was modulated by the presence of various agrochemicals, and because the majority of agrochemicals affected the lag-time duration, we assumed that these compounds could also affect the $\alpha$-synuclein structure. Therefore, the ATR-FTIR and far-UV $\mathrm{CD}$ analyses were used to qualitatively assess structural changes induced in $\alpha$-synuclein in the presence of pesticides (Figures 6 and 7). To this end, samples at the end of the fibrillation process were subjected to ultracentrifugation to separate soluble and insoluble fractions. As previously stated, at physiologic $\mathrm{pH}$, monomeric $\alpha$-synuclein possesses properties characteristic of a natively unfolded protein. In FTIR, this is reflected in a characteristic broad, featureless amide I spectrum centered at $1650 \mathrm{~cm}^{-1}$ (data not shown). The fibrillar form of this protein (as well as all other proteins studied so far) is known to be characterized by a dramatic increase in the $\beta$-sheet structure, ${ }^{38}$ which is reflected in the appearance of a new band at $\sim 1626 \mathrm{~cm}^{-1}$ (see Figure 6). As expected, in the ATR-FTIR spectroscopic analysis, fibrillar samples obtained as pellets after the ultracentrifugation of the reaction mixture at the end of the fibrillation process showed a major $\beta$-sheet contribution (Figure 6A). The analysis of the supernatant samples demonstrated that the soluble aggregated forms of $\alpha$-synuclein were also characterized by the presence of some ordered $\beta$-structure character. Figure 6 shows that the amount of ordered secondary structure in both the soluble and insoluble fractions of the fibrillated control sample depended on the protein concentration, with more $\beta$-structure being formed at higher $\alpha$-synuclein content. In the presence of agrochemicals, the insoluble fractions of the $35 \mu \mathrm{M} \alpha$-synuclein fibrillation mixture were characterized by $\beta$-structure, content of which varied over a wide range, from the levels comparable to (or slightly less than) the $\beta$-sheet content in the $35 \mu \mathrm{M}$ control to the levels approaching the $\beta$-structure content in the $70 \mu \mathrm{M}$ control. Another important observation is that all the agrochemical studied were able to induce more ordered secondary structure in the soluble fraction of $\alpha$-synuclein. In fact, if the FTIR spectra of the soluble fractions of the 35 and $70 \mu \mathrm{M}$ controls were relatively similar to each other and close to the spectrum of the natively unfolded protein (see Figure 6B), than the addition of agrochemicals stabilized a new conformation with enhanced levels of ordered structure. The amount of $\beta$-structure varied from compound to compound indicating that some agrochemicals were able to induce structural changes more efficiently than others.

Figure 7 illustrates the effect of different DDT concentrations on the far-UV CD spectra of $\alpha$-synuclein. Because these measurements were done after only 10 minutes of protein incubation with the pesticide, this figure characterizes structural changes induced in the protein by DDT at the 

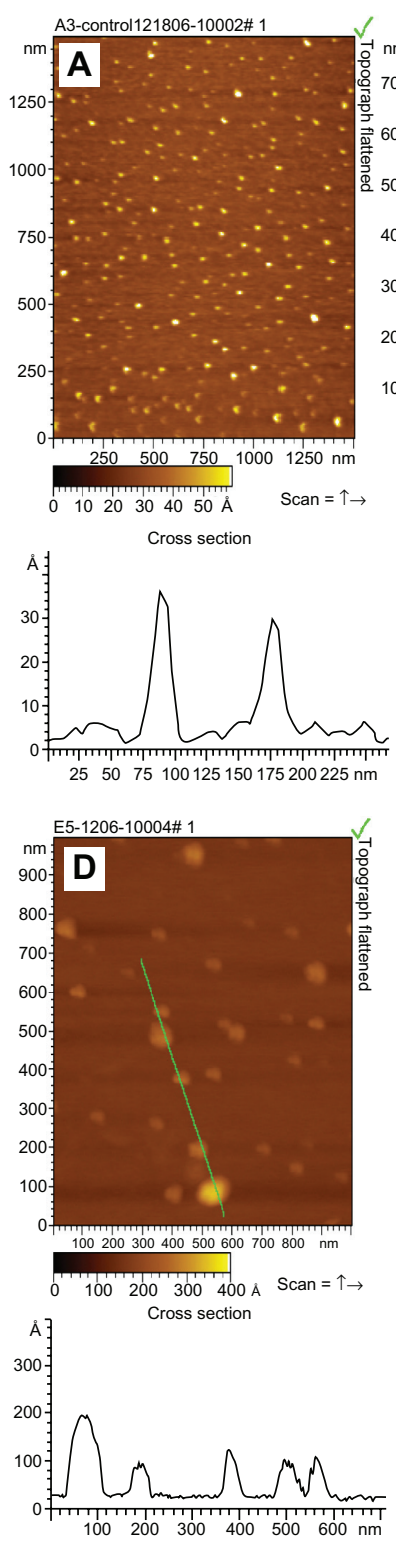
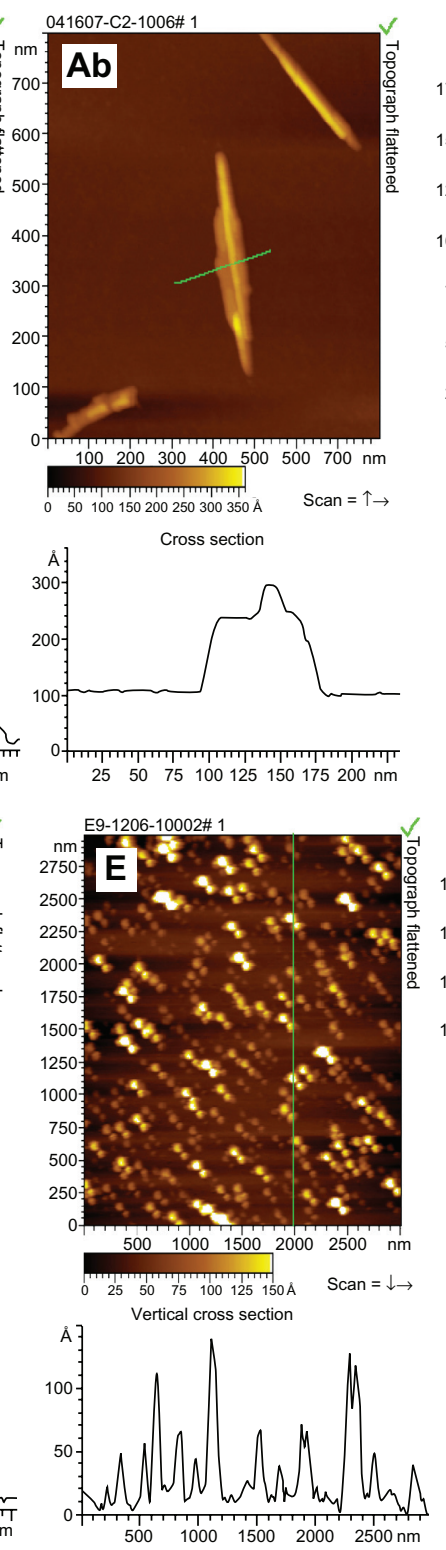
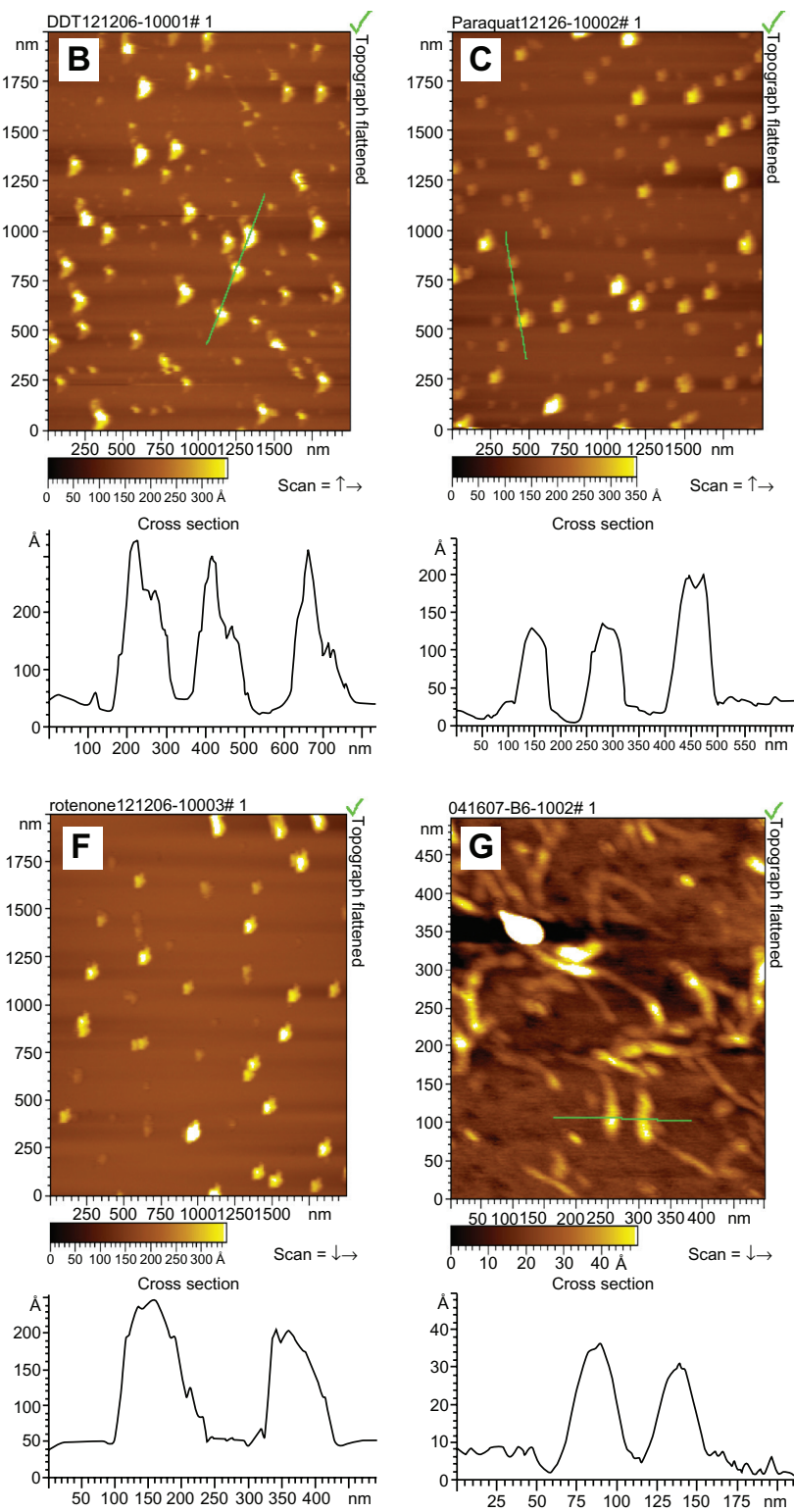
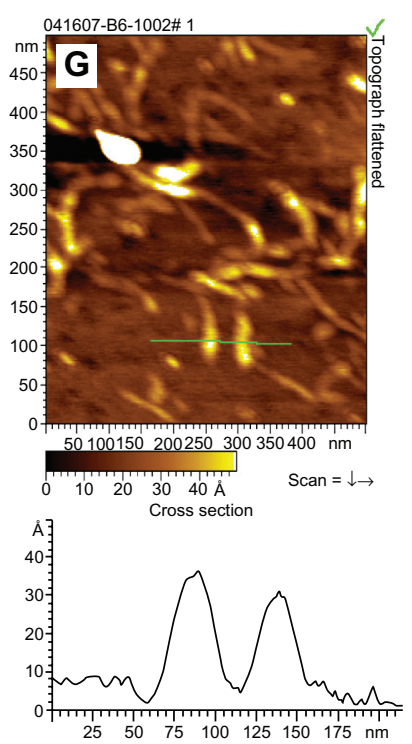

Figure 4 Atomic force micrographs of $35 \mu \mathrm{M} \alpha$-synuclein fibrillated and aggregated in the absence (Aa and $\mathbf{A b}$ ) or the presence of selected agrochemicals: DDT (B), paraquat $(\mathbf{C})$, chlorthal $(\mathbf{D})$, diuron $(\mathbf{E})$, rotenone $(\mathbf{F})$, and kepone $(\mathbf{G})$. Selected measured areas are shown and represent averages of overall species in a given micrograph. Samples contained small aggregates with thickness of $2.8-3.5 \mathrm{~nm}$, large aggregates with widths (or thickness) ranging from 15 to $20 \mathrm{~nm}$, protofibrils with thickness or widths of 6-12 nm, and fibrils with thickness or widths of $15-25 \mathrm{~nm}$. Samples for the AFM analysis were taken prior the beginning of the fibrillation process (except for kepone). Abbreviations: AFM, atomic force microscopy; DDT, dichlorodiphenyltrichloroethane.

early $\alpha$-synuclein fibrillation stage. Figure 7 shows that the transition of the natively unfolded $\alpha$-synuclein to a more ordered conformation is dependent on the DDT concentration. Although the detected far-UV CD changes were small, they were consistent with the transition of $\alpha$-synuclein to a more ordered conformation, likely to a pre-molten globulelike state, which in previous studies was shown to be a crucial amyloidogenic species of this protein. ${ }^{38}$

\section{Discussion}

This study examined the effects of a number of commonly used agrochemicals (insecticides, herbicides, and fungicides) on $\alpha$-synuclein structure and aggregation. Despite their chemical differences, the agrochemical- $\alpha$-synuclein interaction typically accelerated the aggregation and fibrillation of $\alpha$-synuclein. In fact, the kinetic ThT fluorescence assay showed that almost all the agrochemicals tested accelerated the fibrillation process. ATR-FTIR analysis of the precipitated material at the end of the fibrillation process showed that $\alpha$-synuclein contained high $\beta$-structure content, consistent with the formation of amyloid-like fibrils characterized by the cross- $\beta$ structure. However, a noticeable fraction of the $\alpha$-synuclein remained in the nonfibrillar form, as demonstrated by ATR-FTIR and AFM analyses of 

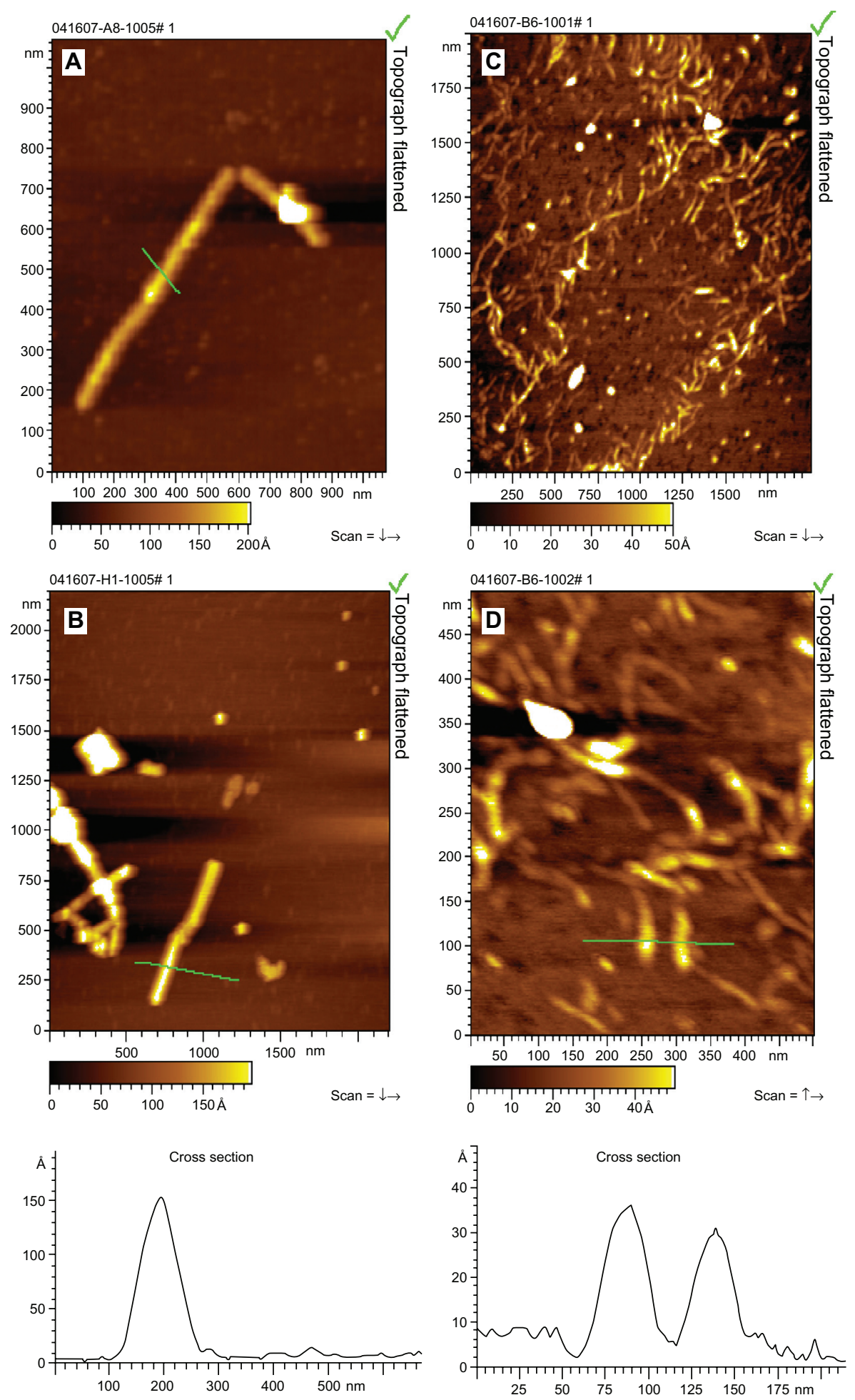

Figure 5 Dependence of the $\alpha$-synuclein fibril morphology on the kepone concentration: $35 \mu M(\mathbf{A}$ and $\mathbf{B})$ and $350 \mu M(\mathbf{C}$ and $\mathbf{D})$. Selected measured areas are shown and represent averaged morphologies of overall species in a given micrograph.

the supernatant portion at the end of the fibrillation process. Further qualitative structural analyses using far-UV CD spectroscopy showed that the agrochemicals can induce structural changes during the early lag phase of the fibrillation process. The ThT assay, ATR-FTIR, and far-UV $\mathrm{CD}$ results provide insight into how pesticides induce misfolding in $\alpha$-synuclein. The misfolded $\alpha$-synuclein is known have an enhanced propensity to aggregate. ${ }^{38,50,51}$ Morphologies of the $\alpha$-synuclein species at the end of the fibrillation process were analyzed by TEM and AFM. The results of this analysis showed the presence of long, welldefined unbranched fibrils, protofibrils, a number of small 

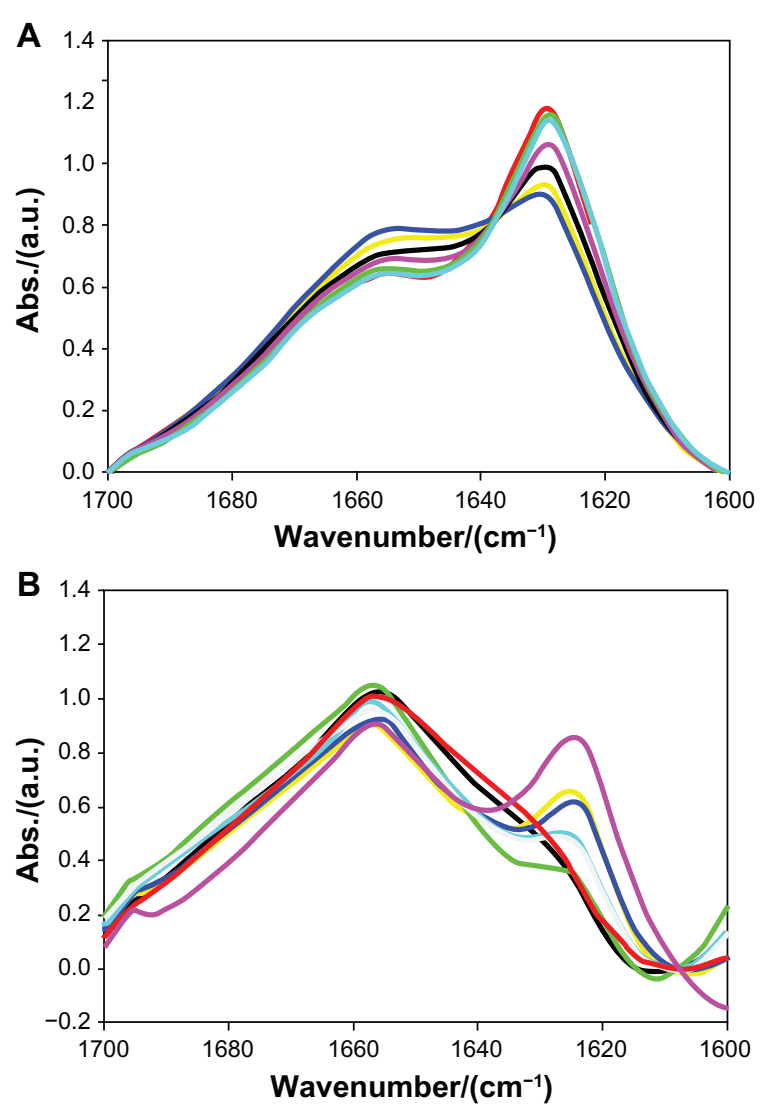

Figure 6 Amide I region ATR-FTIR spectra of $35 \mu \mathrm{M} \alpha$-synuclein fibrillar (A) and soluble aggregated species (B) at the end of fibrillation. Data for kepone, captan, paraquat, ziram, DDE, and rotenone are shown by green, yellow, blue, pink, light blue, and gray lines, respectively. Data for $\alpha$-synuclein aggregated in the absence of agrochemicals at 0.5 and $1.0 \mathrm{mg} / \mathrm{mL}$ are shown by black and red lines respectively. Abbreviations: Abs, absorbance; ATR-FTIR, attenuated total reflectance Fourier transform infrared; a.u. arbitrary units; DDE, dichlorodiphenyldichloroethylene.

and large oligomers, and some amorphous aggregates. The results of the TEM and AFM analyses were generally consistent with the ATR-FTIR results. This suggests that in the presence of agrochemicals, the aggregated species, various oligomers, protofibrils, fibrils, and amorphous aggregates, coexist at the equilibrium phase.

Regardless of the chemical properties and mode of action, the agrochemicals used in this study mostly accelerated the fibrillation process of $\alpha$-synuclein. One common property among the pesticides tested is their hydrophobicity. The information on the hydrophobicity of agrochemicals was extracted from the United States National Library of Medicine-TOXNET hazardous substance data bank (http://toxnet.nlm.nih.gov/cgi-bin/sis/htmlgen?HSDB). The caveat of this analysis is the lack of specific reporting standards for chemicals. In determining the effect of various agrochemicals on the $\alpha$-synuclein fibrillation process, the octanol-water partition coefficient was used as the measure of the compound hydrophobicity. The number

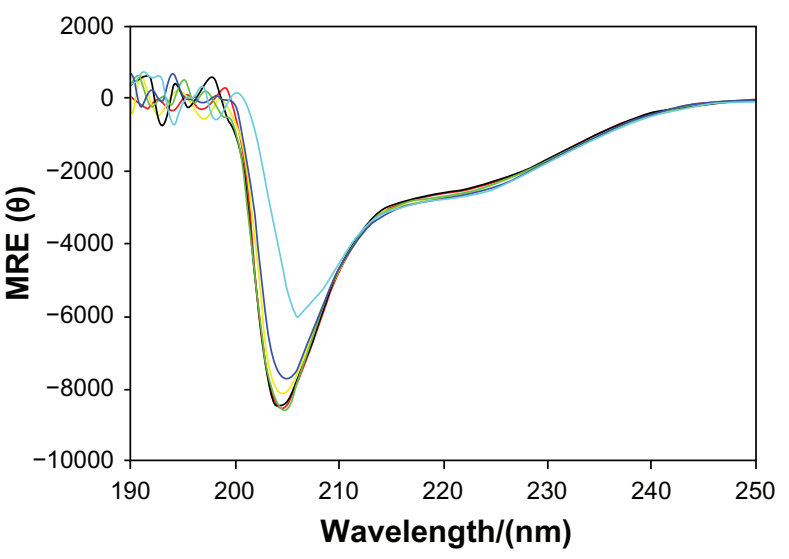

Figure 7 Far-UV CD spectra of monomeric $\alpha$-synuclein $(1 \mathrm{mg} / \mathrm{mL}$ or $70 \mu \mathrm{M})$ in the presence of increasing DDT concentration: 0 (black), I (red), II (green), 61 (yellow), II 3 (blue), 280 (cyan), and 794 (light blue) $\mu \mathrm{M}$. The CD spectra were obtained after a 10-minute incubation period. The spectra represent the average of four scans $(0.1 \mathrm{~mm}$ path-length, $8 \mathrm{sec} / \mathrm{step}$ increment, and $1.5 \mathrm{~nm}$ band-width). These measurements were performed in $20 \mathrm{mM}$ Tris- $\mathrm{HCl}$ buffer at $\mathrm{pH} 7.4$ in the presence of $100 \mathrm{mM} \mathrm{NaCl}$.

Abbreviations: $C D$, circular dichroism; MRE, mean residue ellipticity; UV, ultraviolet.

of halogen atoms and the number of aromatic rings in a given agrochemical were additional properties considered in looking for a correlation between the compound's chemical structure and its effects on the fibrillation process. The results of this analysis are represented in Table 2 and Figure 8.

Figure 8 shows a plot of the the ratio of the lag time of $\alpha$-synuclein in the presence of the agrochemical to the lag time of the control $\alpha$-synuclein lag-time values as a function of the compound hydrophobicity measured as $\log \mathrm{K}_{\mathrm{ow}}$ (where $\mathrm{K}_{\mathrm{ow}}$ is the octanol-water partition coefficient). Figure 8 illustrates that more hydrophobic agrochemicals were typically more effective accelerators of the $\alpha$-synuclein fibrillation. This finding may have important pathological implications. It is known that hydrophobic agrochemicals may impart neurotoxicity in vivo by crossing the blood-brain barrier and by effective accumulation in the brain. ${ }^{52}$ We propose that such hydrophobic agrochemicals, when accumulated in the brain, might efficiently interact with $\alpha$-synuclein, induce misfolding and fibrillation of this protein in vivo, and therefore promote neurodegeneration via the protein misfolding/ aggregation pathway.

While Figure 8 indicates a general trend based on the compounds' hydrophobicity, some hydrophilic agrochemicals may also accelerate the fibrillation of $\alpha$-synuclein. This is illustrated by paraquat, a herbicide commonly used as a watersoluble salt preparation with a $\log \mathrm{K}_{\mathrm{ow}}$ value of -4.22 (Table 2). Although water-soluble, this agrochemical efficiently accelerated the $\alpha$-synuclein fibrillation process in vitro. Paraquat is known to impart neurotoxicity mostly by altering complex 


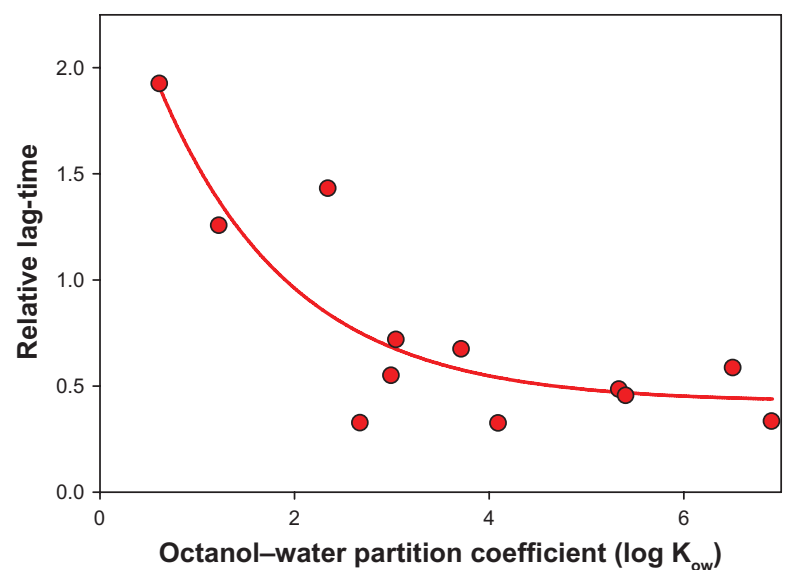

Figure 8 Effect of pesticides hydrophobicity on the $\alpha$-synuclein fibrillation process.

I in the mitochondria of dopamine-producing neurons. ${ }^{11,25}$ Paraquat was reported to utilize an active transport mechanism, being able to cross the blood-brain barrier and accumulate in the brain by the means of a specific carrier. ${ }^{52}$ As a result, paraquat slowly accumulates to significant levels in specific regions of the brain. ${ }^{53}$ Once in the brain, neurotoxicity results from the paraquat, inducing the production of free oxygen radicals, which eventually cause cell damage. We suggest that in addition to all the abovementioned neurotoxic mechanisms, paraquat can directly interact with $\alpha$-synuclein in the brain and promote its aggregation.

Further analysis of the chemical properties of the agrochemicals showed a trend associated with the number of halogen atoms and the number of aromatic rings present in a given compound. Generally, the duration of the fibrillation lag-phase decreased with an increase in the number of halogen atoms and aromatic rings. While our study represents a limited pool sample, a definite trend was established providing evidence that further investigation of the effect of agrochemicals on the $\alpha$-synuclein misfolding and fibrillation is warranted.

\section{Disclosure}

This work was supported in part by the NIH Initiative for Maximizing Student Diversity, grant \# GM058903 (B.S.) and by NIH grant R01 NS39985 (A.L.F.).

\section{References}

1. Uversky VN, Yamin G, Souillac PO, Goers J, Glaser CB, Fink AL. Methionine oxidation inhibits fibrillation of human alpha-synuclein in vitro. FEBS Lett. 2002;517(1-3):239-244.

2. Louis ED, Factor-Litvak P, Parides M, Andrews L, Santella RM, Wolff MS. Organochlorine pesticide exposure in essential tremor: a case-control study using biological and occupational exposure assessments. Neurotoxicology. 2006;27(4):579-586.

3. Ritz B, Yu F. Parkinson's disease mortality and pesticide exposure in California 1984-1994. Int J Epidemiol. 2000;29(2):323-329.
4. Langston JW, Ballard P, Tetrud JW, Irwin I. Chronic parkinsonism in humans due to a product of meperidine-analog synthesis. Science. 1983;219(4587):979-980.

5. Irwin I, Langston JW. Selective accumulation of MPP+ in the substantia nigra: a key to neurotoxicity? Life Sci. 1985;36(3):207-212.

6. Langston JW, Forno LS, Tetrud J, Reeves AG, Kaplan JA, Karluk D. Evidence of active nerve cell degeneration in the substantia nigra of humans years after 1-methyl-4-phenyl-1,2,3,6-tetrahydropyridine exposure. Ann Neurol. 1999;46(4):598-605.

7. McCormack AL, Thiruchelvam M, Manning-Bog AB, et al. Environmental risk factors and Parkinson's disease: selective degeneration of nigral dopaminergic neurons caused by the herbicide paraquat. Neurobiol Dis. 2002;10(2):119-127.

8. Uversky VN, Li J, Fink AL. Pesticides directly accelerate the rate of alpha-synuclein fibril formation: a possible factor in Parkinson's disease. FEBS Lett. 2001;500(3):105-108.

9. Uversky VN, Li J, Fink AL. Metal-triggered structural transformations, aggregation, and fibrillation of human alpha-synuclein. A possible molecular NK between Parkinson's disease and heavy metal exposure. J Biol Chem. 2001;276(47):44284-44296.

10. Uversky VN, Li J, Bower K, Fink AL. Synergistic Effects of pesticides and metals on fibrillation of a-synuclein: implications for Parkinson's Disease. Neurotoxicology. 2002;23(4-5):527-536.

11. Manning-Bog AB, McCormack AL, Li J, Uversky VN, Fink AL, di Monte DA. The herbicide paraquat causes up-regulation and aggregation of alpha-synuclein in mice: paraquat and alpha-synuclein. J Biol Chem. 2002;277(3):1641-1644.

12. Kuhn K, Wellen J, Link N, Maskri L, Lubbert H, Stichel CC. The mouse MPTP model: gene expression changes in dopaminergic neurons. Eur J Neurosci. 2003;17(1):1-12.

13. Moore DJ, West AB, Dawson VL, Dawson TM. Molecular pathophysiology of Parkinson's disease. Annu Rev Neurosci. 2005;28: 57-87.

14. Cory-Slechta DA, Thiruchelvam M, Barlow BK, Richfield EK. Developmental pesticide models of the Parkinson disease phenotype. Environ Health Perspect. 2005;113(9):1263-1270.

15. Kaylor J, Bodner N, Edridge S, Yamin G, Hong DP, Fink AL. Characterization of oligomeric intermediates in alpha-synuclein fibrillation: FRET studies of Y125W/Y133F/Y136F alpha-synuclein. J Mol Biol. 2005;353(2):357-372.

16. Parkinson J. An essay on the shaking palsy. 1817. J Neuropsychiatry Clin Neurosci. 2002;14(2):223-236; discussion 222.

17. Dick FD, de Palma G, Ahmadi A, et al. Environmental risk factors for Parkinson's disease and parkinsonism: the Geoparkinson study. Occup Environ Med. 2007;64(10):666-672.

18. Corrigan FM, Wienburg CL, Shore RF, Daniel SE, Mann D. Organochlorine insecticides in substantia nigra in Parkinson's disease. J Toxicol Environ Health A. 2000;59(4):229-234.

19. Rao JN, Dua V, Ulmer TS. Characterization of alpha-synuclein interactions with selected aggregation-inhibiting small molecules. Biochemistry. 2008;47(16):4651-4656.

20. Doherty JD. Screening pesticides for neuropathogenicity. J Biomed Biotechnol. 2006;2006(3):70414.

21. Uversky VN, Fink AL. Biophysical properties of human $\alpha$-synuclein and its role in Parkinson's disease. Recent Research Dev Proteins. 2002;1:153-186.

22. Uversky VN. Neuropathology, biochemistry, and biophysics of alpha-synuclein aggregation. J Neurochem. 2007;103(1): $17-37$.

23. Li S, Crooks PA, Wei X, de Leon J. Toxicity of dipyridyl compounds and related compounds. Crit Rev Toxicol. 2004;34(5):447-460.

24. Sherer TB, Betarbet R, Testa CM, et al. Mechanism of toxicity in rotenone models of Parkinson's disease. J Neurosci. 2003;23(34): 10756-10764.

25. McCormack AL, Atienza JG, Johnston LC, Andersen JK, Vu S, di Monte DA. Role of oxidative stress in paraquat-induced dopaminergic cell degeneration. J Neurochem. 2005;93(4):1030-1037. 
26. Betarbet R, Canet-Aviles RM, Sherer TB, et al. Intersecting pathways to neurodegeneration in Parkinson's disease: effects of the pesticide rotenone on DJ-1, alpha-synuclein, and the ubiquitin-proteasome system. Neurobiol Dis. 2006;22(2):404-420.

27. Conway KA, Harper JD, Lansbury PT. Accelerated in vitro fibril formation by a mutant alpha-synuclein linked to early-onset Parkinson disease. Nat Med. 1998;4(11):1318-1320.

28. Conway KA, Harper JD, Lansbury PT Jr. Fibrils formed in vitro from alpha-synuclein and two mutant forms linked to Parkinson's disease are typical amyloid. Biochemistry. 2000;39(10): 2552-2563.

29. Munishkina LA, Phelan C, Uversky VN, Fink AL. Conformational behavior and aggregation of alpha-synuclein in organic solvents: modeling the effects of membranes. Biochemistry. 2003;42(9): 2720-2730.

30. De Ferrari GV, Mallender WD, Inestrosa NC, Rosenberry TL. Thioflavin $\mathrm{T}$ is a fluorescent probe of the acetylcholinesterase peripheral site that reveals conformational interactions between the peripheral and acylation sites. J Biol Chem. 2001;276(26):23282-23287.

31. Khurana R, Coleman C, Ionescu-Zanetti C, et al. Mechanism of thioflavin T binding to amyloid fibrils. J Struct Biol. 2005;151(3): 229-238.

32. Uversky VN. Neurotoxicant-induced animal models of Parkinson's disease: understanding the role of rotenone, maneb and paraquat in neurodegeneration. Cell Tissue Res. 2004;318(1):225-241.

33. Nielsen L, Khurana R, Coats A, et al. Effect of environmental factors on the kinetics of insulin fibril formation: elucidation of the molecular mechanism. Biochemistry. 2001;40(20):6036-6046.

34. Khurana R, Uversky VN, Nielsen L, Fink AL. Is Congo red an amyloidspecific dye? J Biol Chem. 2001;276(25):22715-22721.

35. Nielsen L, Frokjaer S, Brange J, Uversky VN, Fink AL. Probing the mechanism of insulin fibril formation with insulin mutants. Biochemistry. 2001;40(28):8397-8409.

36. Oberg KA, Fink AL. A new attenuated total reflectance Fourier transform infrared spectroscopy method for the study of proteins in solution. Anal Biochem. 1998;256(1):92-106.

37. Fink AL. Methods for Collecting and Analyzing Attenuated Total Reflectance FTIR Spectra of Proteins in Solution. New York, NY: Academic Press Inc.; 1995.

38. Uversky VN, Li J, Fink AL. Evidence for a partially folded intermediate in alpha-synuclein fibril formation. J Biol Chem. 2001;276(14): 10737-10744.

39. Uversky VN, Li J, Bower K, Fink AL. Synergistic effects of pesticides and metals on the fibrillation of alpha-synuclein: implications for Parkinson's disease. Neurotoxicology. 2002;23(4-5):527-536.
40. Emborg ME. Evaluation of animal models of Parkinson's disease for neuroprotective strategies. J Neurosci Methods. 2004;139(2): 121-143.

41. Coppede F, Mancuso M, Siciliano G, Migliore L, Murri L. Genes and the environment in neurodegeneration. Biosci Rep. 2006;26(5):341-367.

42. Von Bohlen und Halbach O, Schober A, Krieglstein K. Genes proteins and neurotoxins involved in Parkinson's disease. Prog Neurobiol. 2004; 73(3):151-177.

43. Ulmer TS, Bax A, Cole NB, Nussbaum RL. Structure and dynamics of micelle-bound human alpha-synuclein. J Biol Chem. 2005;280(10): 9595-9603.

44. Levine H 3rd. Soluble multimeric Alzheimer beta(1-40) pre-amyloid complexes in dilute solution. Neurobiol Aging. 1995;16(5):755-764.

45. Naiki H, Higuchi K, Hosokawa M, Takeda T. Fluorometric determination of amyloid fibrils in vitro using the fluorescent dye, thioflavin T1. Anal Biochem. 1989;177(2):244-249.

46. Naiki H, Higuchi K, Matsushima K, et al. Fluorometric examination of tissue amyloid fibrils in murine senile amyloidosis: use of the fluorescent indicator, thioflavine T. Lab Invest. 1990;62(6):768-773.

47. Thiruchelvam M, Brockel BJ, Richfield EK, Baggs RB, Cory-Slechta DA. Potentiated and preferential effects of combined paraquat and maneb on nigrostriatal dopamine systems: environmental risk factors for Parkinson's disease? Brain Res. 2000;873(2): 225-234.

48. Yamin G, Munishkina LA, Karymov MA, Lyubchenko YL, Uversky VN, Fink AL. Forcing nonamyloidogenic beta-synuclein to fibrillate. Biochemistry. 2005;44(25):9096-9107.

49. Murphy RM, Tsai AM. Misbehaving Proteins: Protein (Mis)folding, Aggregation, and Stability. New York, NY: Springer; 2006.

50. Uversky VN, Fink AL. Structural effect of association on protein molecules in partially folded intermediates. Biochemistry (Mosc). 1998; 63(4):456-462.

51. Uversky VN, Lee HJ, Li J, Fink AL, Lee SJ. Stabilization of partially folded conformation during alpha-synuclein oligomerization in both purified and cytosolic preparations. J Biol Chem. 2001;276(47): 43495-43498.

52. Shimizu K, Ohtaki K, Matsubara K, et al. Carrier-mediated processes in blood-brain barrier penetration and neural uptake of paraquat. Brain Res. 2001;906(1-2):135-142.

53. Corasaniti MT, Strongoli MC, Rotiroti D, Bagetta G, Nistico G. Paraquat: a useful tool for the in vivo study of mechanisms of neuronal cell death. Pharmacol Toxicol. 1998;83(1):1-7.
Research and Reports in Biology

\section{Publish your work in this journal}

Research and Reports in Biology is an international, peer-reviewed, open access journal publishing original research, reports, editorials, reviews and commentaries on all areas of biology including animal biology, biochemical biology, cell biology, ecological studies, evolutionary biology, molecular biology, plant science and botany. The

\section{Dovepress}

manuscript management system is completely online and includes a very quick and fair peer-review system. Visit http://www.dovepress. com/testimonials.php to read real quotes from published authors. 